\title{
Comparison between the performance of a Movable boards Ditch opener and the conventional ditch opener in cultivated and uncultivated soils
}

\section{Part 2: The disturbed area}

\author{
${ }^{1}$ Shaker H. Aday \\ ${ }^{2}$ Yarub W. Al-Muthafar \\ ${ }^{1,2}$ Dept. of machines and equipment, College of Agriculture, University of Basrah, \\ Basrah, Iraq \\ shaker.h.1953@gmail.com
}

\begin{abstract}
The performance of the movable boards ditch opener (MB) and the conventional ditch opener (CD) was compared using the disturbed area as a comparison parameter to determine the best among the two implements. The experimental factors were three operating depths $(30,40$ and $50 \mathrm{~cm})$ for $\mathrm{MB}$ in the cultivated and uncultivated soils, while for CD in the cultivated soil only, because it could not penetrate the uncultivated soil more than $(25 \mathrm{~cm})$, three angles between the boards of MB $\left(45,60\right.$ and $\left.75^{\circ}\right)$ and one angle between the boards of $\mathrm{CD}\left(65^{\circ}\right)$ (the angle between the boards of $\mathrm{CD}$ was constant because its boards were welded together), three wings widths of the foot of MB $(25,35$ and $45 \mathrm{~cm})$ whereas, one share width $(35 \mathrm{~cm})$ for $\mathrm{CD}$ (for $\mathrm{MB}$ the wings can be changed by another wings of wider width whereas for $\mathrm{CD}$ it was provided with share permanently fixed at the lower end of the boards) and two soil conditions (cultivated and uncultivated soils).

The results showed that DA (the disturbed area, the cross-section area of the soil manipulated by the implements) for $\mathrm{CD}$ and $\mathrm{MB}$ increased with operating depth and it was higher in the cultivated soil compared with that in the uncultivated soil for MB only. DA increased with increasing the angle between the boards of MB whereas, for CD the angle was constant so that DA was constant. DA also increased with wings width of the foot of $\mathrm{MB}$ while, for $\mathrm{CD}$ the width was constant also, so that the DA was constant.

The operating depth increased DA more than the angle between the boards, the width of the wings of the foot and the soil conditions. Whereas the angle between the boards surpassed the width of the foot and soil conditions in giving higher DA. However, the width of the wings surpassed the soil conditions in giving higher DA. This means MB gave higher performance than $\mathrm{CD}$ in both soil conditions. It also penetrated the uncultivated soil down to $50 \mathrm{~cm}$ despite of its great resistance whereas, CD could not penetrate this soil type more than $25 \mathrm{~cm}$. Thus the field performance of $\mathrm{MB}$ was better than $\mathrm{CD}$. In additional to that, it gave wider cross-section width ditches and deeper ditch in both soil conditions compared with CD.
\end{abstract}

Abbreviation: $\mathrm{MB}=$ Movable boards ditch opener; $\mathrm{CD}=$ Conventional ditch opener; $\mathrm{DA}=$ Cross-section area

\section{Introduction}

The conventional ditch opener (CD) suffers from many drawbacks among them high draft force requirement, high specific resistance, low energy utilization efficiency and its ability in penetrating soils was limited especially in uncultivated soil. In additional to that it produces same cross-section ditches 
throughout the field (Aday and Ramadhan 2018 and Aday et al 2016). Because of these reasons a new ditch opener was designed and tested.

The disturbed area increased as the operating depth increased and it was higher in the uncultivated soil compared with cultivated soil (Ahmed and Godwin 1983 and Aday et al 2011). The disturbed area also increased when the implement was provided with wings (Godwin and Spoor 1977 and Owen 1988). The wings widen the disturbed soil at depth and increasing the width at the soil surface and that was because the wings create cracks develop from the wings edges towards the soil surface (Mckyes and Maswaure 1997). The cracks develop sideways at first and then grew inclined paths continuously until they meet the soil surface (Aday and Hillal 2004a and 2004b and Spoor and Godwin 1978).

The disturbed area is considerably depends on the soil moisture content. It increased significantly in the soil friable state compared with soil hard and plastic states. With high soil moisture content the soil adhered the implements and that reduces the disturbed area. The addition of shallow tines and wings to the subsoiler improved the disturbed area considerably. The disturbed area doubled with addition the shallow tines and wings to the foot of the subsoiler with 20 to $30 \%$ increase in the draft force.

The aim of this work was designing new implement can penetrate the soils easily to the required depth in all soils different conditions. The new implement (MB) field performance was evaluated by comparing it with that of the conventional ditch opener (CD) using the disturbed area as comparing parameter. The comparison was to determine the best performance out of the two implements.

\section{I.1 Materials and Methods}

CD consists of a frame, two fixed boards the angle between them was constant $\left(65^{\circ}\right)$ and wide share of constant width of $35 \mathrm{~cm}$. The boards edges were sharp. They are used to cut the sides of the ditches made by the machine, Fig. 1. Due to the withdraw backs which CD suffers from a new implement was designed to open different cross-section widths ditches this implement is call movable boards ditch opener. MB consists of a frame made of steel to withstand the stress created by the soil on the implement and subsoiler which consists of a Leg (shank ) and foot fix at the lower end of the leg, Fig.2. The forward inclination angle (rake angle) of the leg was $60^{\circ}$. The foot was provided with wings. The inclination angle of the wings relative to the horizontal line was $30^{\circ}$. The attack angle (penetration angle) of the foot front was $25^{\circ}$. The subsoiler was fixed tightly to the implement frame. The implement was provided with two boards. The length and width of each board were 100 and $75 \mathrm{~cm}$ respectively. A steel shaft of $25 \mathrm{~mm}$ diameter was fixed behind the leg. 


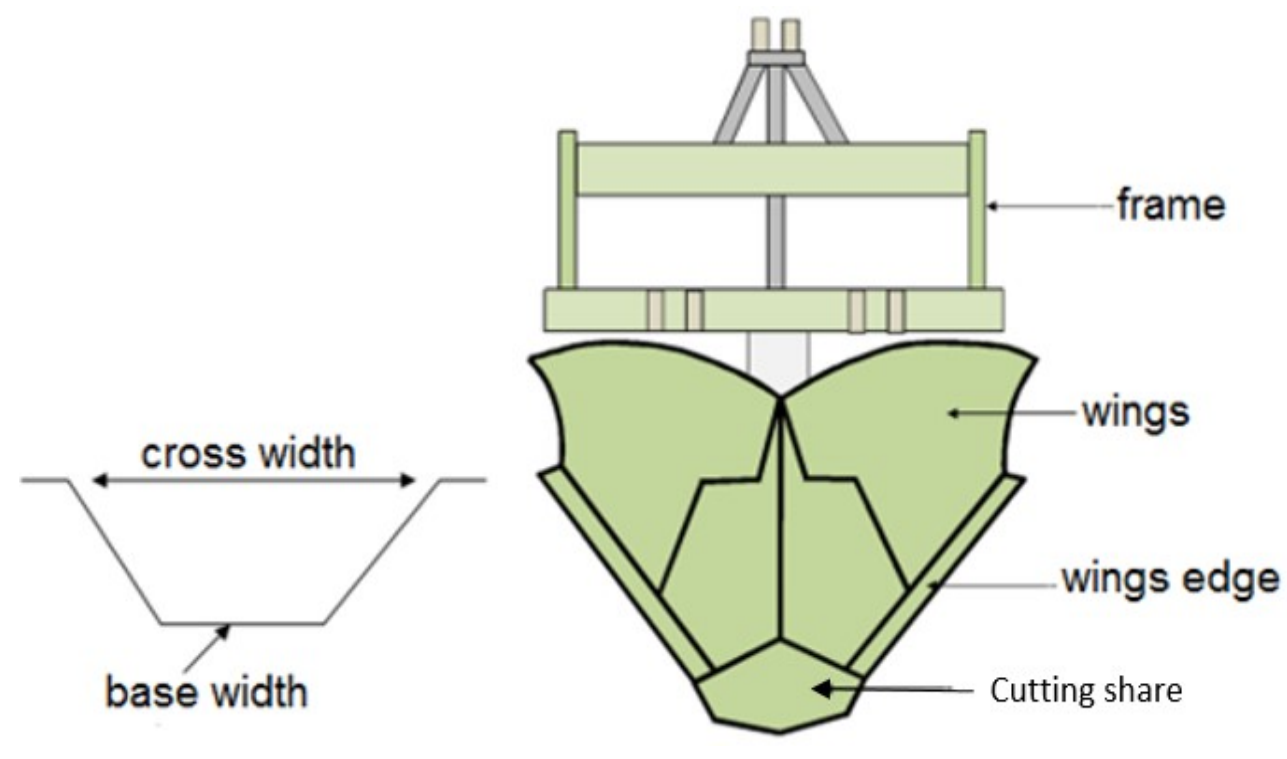

Fig.(1): The conventional ditch opener

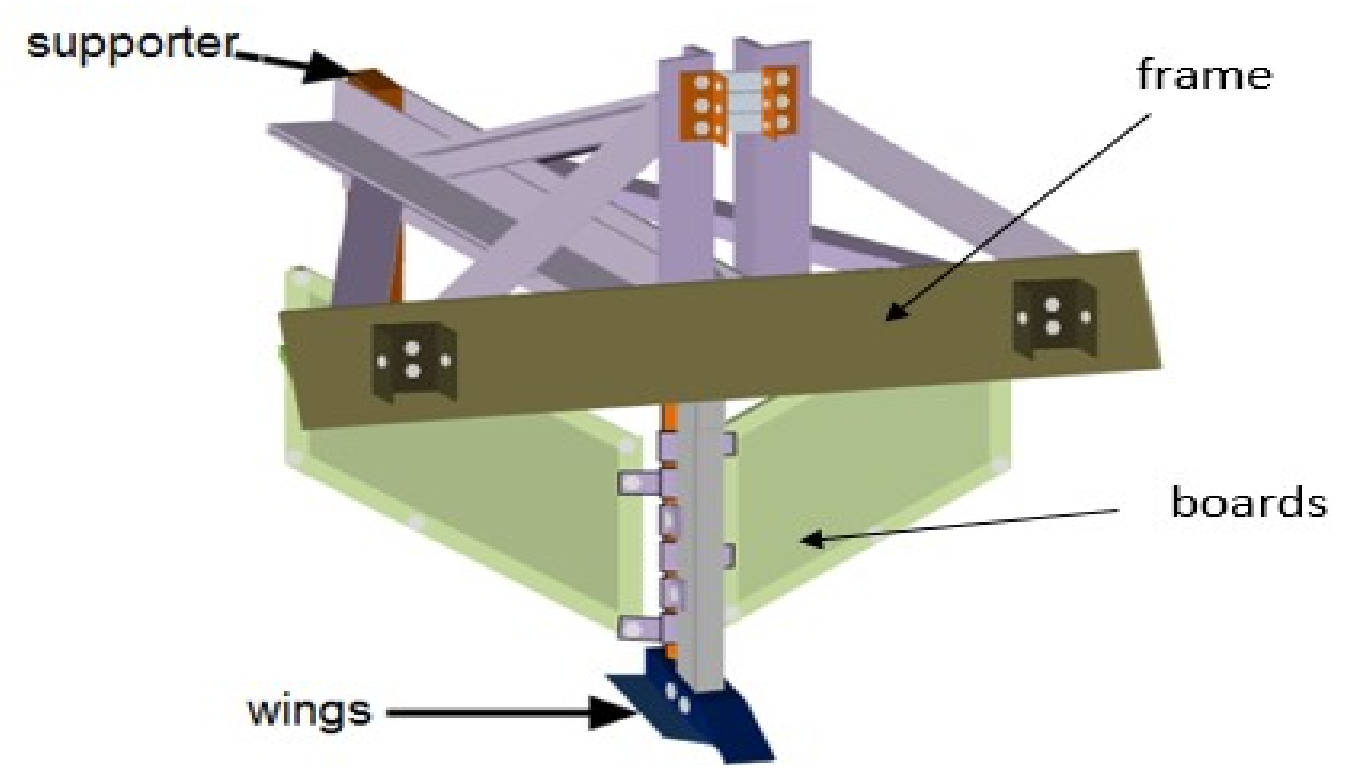

(A): geometrical view 


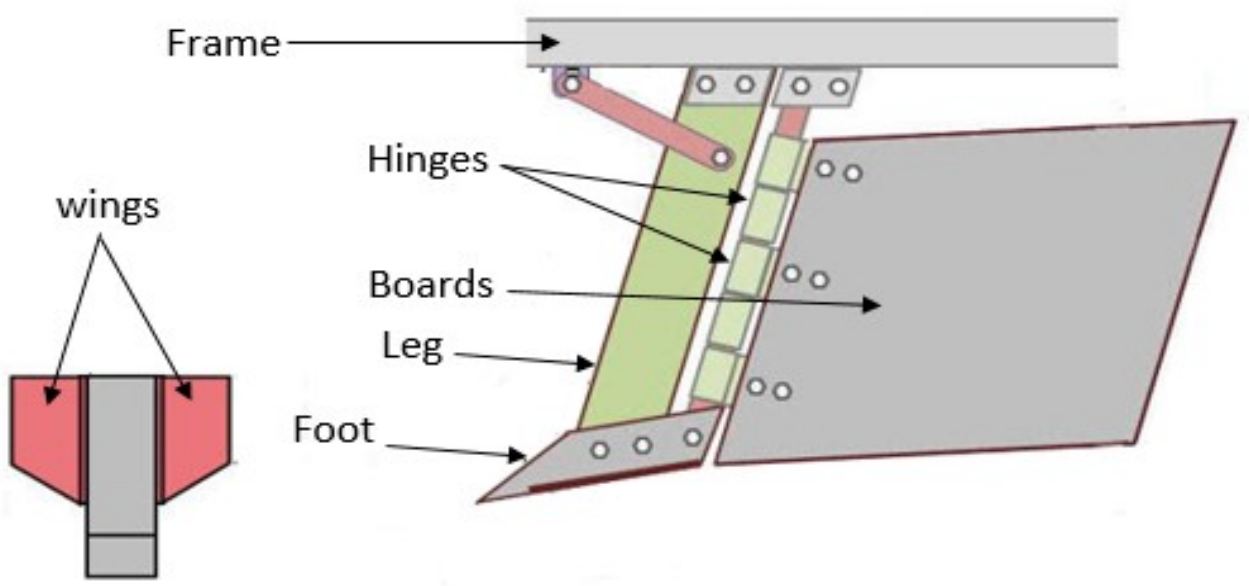

Fig. (2): the movable boards ditch opener

The two boards were attached behind to the shaft by hinged method. The hinges permit the two boards to move freely in and out the center line of the implement and that enabled the machine angles between the two boards. This method of boards attachment enabled the implement to have different angles between them. The two boards was provided with telescopic bar fixed between them to get different angles. The lower edges of the two boards made with soil surface angle of $45^{0}$ to prevent the boards skidding on the soil surface. To prevent the side movement of the two boards when they suffered from unequal side force, the top edge of one board was provided with support bar fixed to the frame from one side and to the frame from the other side. The top edge was provided with many holes to choose one of them coincide with angle between the two boards.

\section{The soil properties measurement}

The bulk density and the moisture content of both soils were measured using methods descried in Black (1983) (table 1). The soil strength parameters, the cohesion and the internal friction angle, and the soil penetration index were measured by the Annual ring and the penetrometer tool using the methods described by Gill and Vander (1968). The results are shown in table (2).

\section{The experiments parameters}

MB was tested in the field using three operating depths $(30,40$ and $50 \mathrm{~cm})$ and three angles between the movable boards of $\mathrm{MB}\left(45,60\right.$ and $\left.75^{\circ}\right)$. The experiments were carried out in cultivated and uncultivated soils. CD was also tested using three operating depths $(30,40$ and $50 \mathrm{~cm})$ in the cultivated soil and one depth $(25 \mathrm{~cm})$ in the uncultivated soil because it could not penetrate the soil more than this depth. The angle between $\mathrm{CD}$ boards was constant $\left(65^{\circ}\right)$, its board were fixed on the frame. The soil texture was silty clay.

\section{III. measurement of the disturbed area}

The cross-section area of the ditches made by $\mathrm{CD}$ and $\mathrm{MB}$ were measured in the field for all operating depth, angles between the boards and in both soil types. The disturbed soil was dogged out by 
hand to keep the ditch sides undisturbed until the disturbed soil completely out of the ditch bottom. The widths of the ditch at the soil surface and bottom and its depth were measured. The measurements were repeated for different position for each operating depth, angle between boards and in both soil types, Fig 3 .

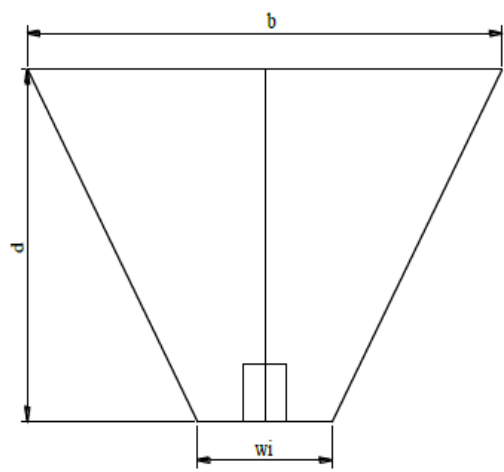

(2)

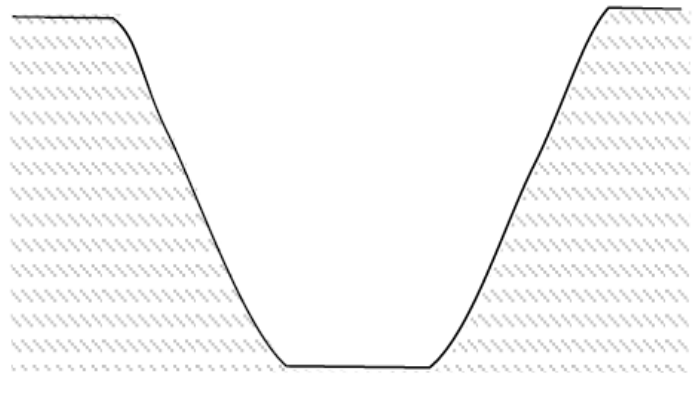

(1)

Fig. (3): the cross-section area of the ditch

The cross-section area of the ditch was calculated using Eq.1

$A=W i \cdot d+\frac{(b-W i)}{2} d$

\section{Results and discussion}

1- The effect of the operating depth and the soil types on the disturbed area.

DA increased considerably for both implements in the cultivated soil. For MB, DA increased from 0.16 to $0.35 \mathrm{~m}^{2}(118 \%)$. This means increasing the operating depth from 30 to $50 \mathrm{~cm}(20 \mathrm{~cm}$ only) DA was more than doubled. For CD, DA increased from 0.15 to $0.37 \mathrm{~m}^{2}(146 \%)$. The considerable increase in DA in the cultivated soil was due to the weakness of the soil strength which enabled the two implements to penetrate the soil easily and disturb greater volume of soil (Aday and Al-Haliphy 2001 and Godwin and Spoor 1977). In additional to that the width of the disturbed soil at soil surface increased considerable with depth as well as the edges of the boards cut through ditch sides which widen the ditch cross-section area from bottom to the soil surface especially with CD.

In the uncultivated soil the performance of $\mathrm{CD}$ completely changed, it could not penetrate the soil more than $25 \mathrm{~cm}$, so that DA produced by $\mathrm{CD}$ was $0.13 \mathrm{~m}^{2}$ only. For $\mathrm{MB}$, it penetrated the soil easily down to depth of $50 \mathrm{~cm}$ (it would be more if a power were available). Thus DA for MB increased from 0.162 to $0.35 \mathrm{~m}^{2}(116 \%)$ when the operating depth increased from 30 to $50 \mathrm{~cm}$. In general, the performance of MB surpassed that of $\mathrm{CD}$, it could penetrate the soil to the required depth whether the soil was cultivated or uncultivated, whereas, the contrary occurred with $\mathrm{CD}$ where it could not penetrate the uncultivated soil.

Comparing $\mathrm{DA}$ of $\mathrm{CD}$ and that of $\mathrm{MB}$, there is margin supervision for $\mathrm{CD}$ on $\mathrm{MB}$ in operating depths of 40 and $50 \mathrm{~cm}$ in cultivated soil. The differences were only $0.1 \mathrm{~m}^{2}(3.8 \%)$ and $0.2 \mathrm{~m}^{2}(5.7 \%)$ for the operating depths 40 and $50 \mathrm{~cm}$ respectively. However, in the uncultivated soil, MB clearly supervised CD in 
having greater DA, (CD could not penetrate the soil more than $25 \mathrm{~cm}$ ), for example, DA produced by MB at operating depth of $50 \mathrm{~cm}$ was greater than that of CD by $169 \%$.

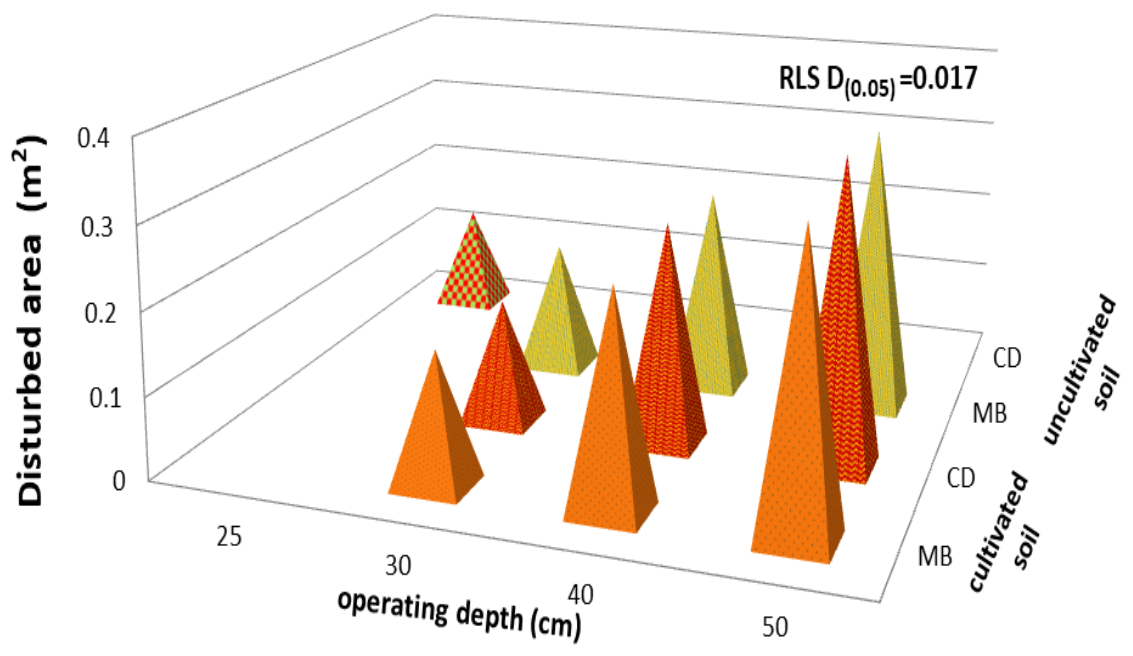

Fig. (4): the relationship between the disturbed area and the operating depth of $\mathrm{CD}$ and $\mathrm{Mb}$ in two soil types.

The effect of interaction between the operating depth and the angle between the boards of the implements on the disturbed area of CD and MB.

The effect of the operating depths and the angle between the boards on DA of CD and MB is shown in Fig. (5). DA for MB increased considerably with operating depths for all angle between the boards. The rate of increase in DA was greater for the higher values of angle while it was lower for the smaller angles. For example, for angle of $45^{\circ}$, DA increased from 0.1448 to $0.288 \mathrm{~m}^{2}(99 \%)$, whereas, for angle of $60^{\circ}$ it increase from 0.1528 to $0.3368 \mathrm{~m}^{2}(120 \%)$, However, for angle of $75^{\circ} \mathrm{DA}$ increased from 0.1821 to $0.4111 \mathrm{~m}^{2}(126 \%)$. The reason was that as the angle between the boards of MB increased, they cut through the ditch sides which resulted in wider ditch, i.e greater cross-area of the ditch. $\mathrm{CD}$

For CD there was one angle between its board $\left(65^{\circ}\right)$ thus the angle did not affect DA produced by

The results showed for MB only the effect of the angle between its boards on DA was more decisive as the operating depth increased. For example, for operating depth of $30 \mathrm{~cm}$, changing the angle from $45^{\circ}$ to $75^{\circ}$, DA increased from 0.1448 to $0.1821(26 \%)$, whereas, for operating depth of $50 \mathrm{~cm} \mathrm{DA}$, increased from 0.2888 to $0.4111 \mathrm{~m}^{2}(42 \%)$. This means to obtain ditch of greater cross-section area wider angle between the boards should be used.

The results showed clearly the supervision of MB performance on the that of CD. 


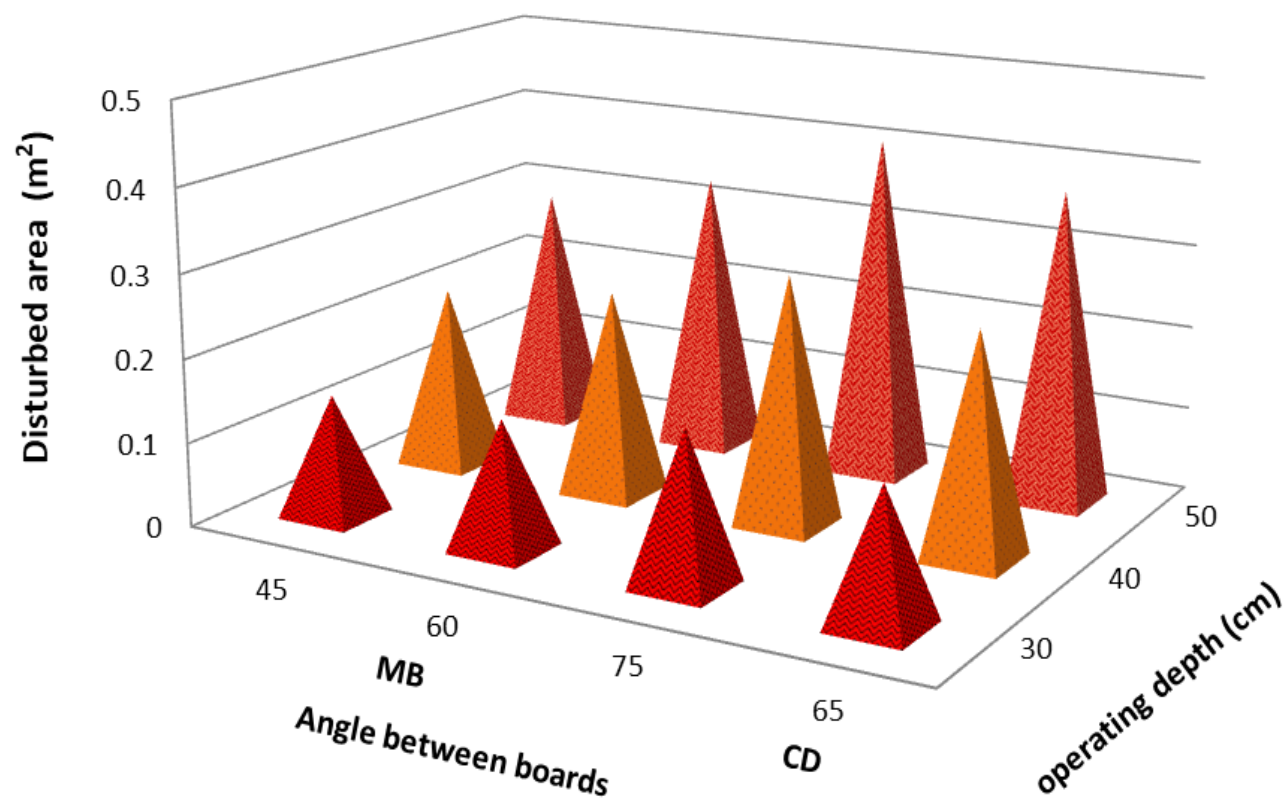

Fig. (5): The relationship between the disturbed area for MB and $C D$ and the operating depth for different angles between the boards of MB.

The interaction effect of the soil conditions and the angles between the boards on the disturbed area by MB and CD

The effect of the soil conditions and the angle between the boards on the DA for MB and CD is shown in Fig. (6). MB supervised CD in giving higher DA for all angles between the boards in uncultivated soil. CD in this soil type could not penetrate the soil more than $25 \mathrm{~cm}$ thus its DA at this operating depth and angle of $65^{\circ}$ (constant angle) is $0.132 \mathrm{~m}^{2}$. However, DA for MB in this soil type was high than that for CD by $57 \%, 80 \%$ and $126.5 \%$ for angles 45,60 and $75^{\circ}$ respectively. The supervision of MB on CD in giving greater DA is related to its higher ability in penetrating the uncultivated soil to the required depth regardless of soil hardness whereas, CD could not penetrate the soil more than $25 \mathrm{~cm}$.

In the cultivated soil, both implements penetrated the soil. However, MB at angle of $75^{\circ}$ supervised $\mathrm{CD}$ at angle of $65^{\circ}$ in giving higher DA a. For angles 45 and $60^{\circ}$ of $\mathrm{MB}, \mathrm{CD}$ at angle of $65^{\circ}$ supervised $\mathrm{MB}$ but with limited amount especially with angle of $60^{\circ}$. This was because CD had greater angle between the boards. 


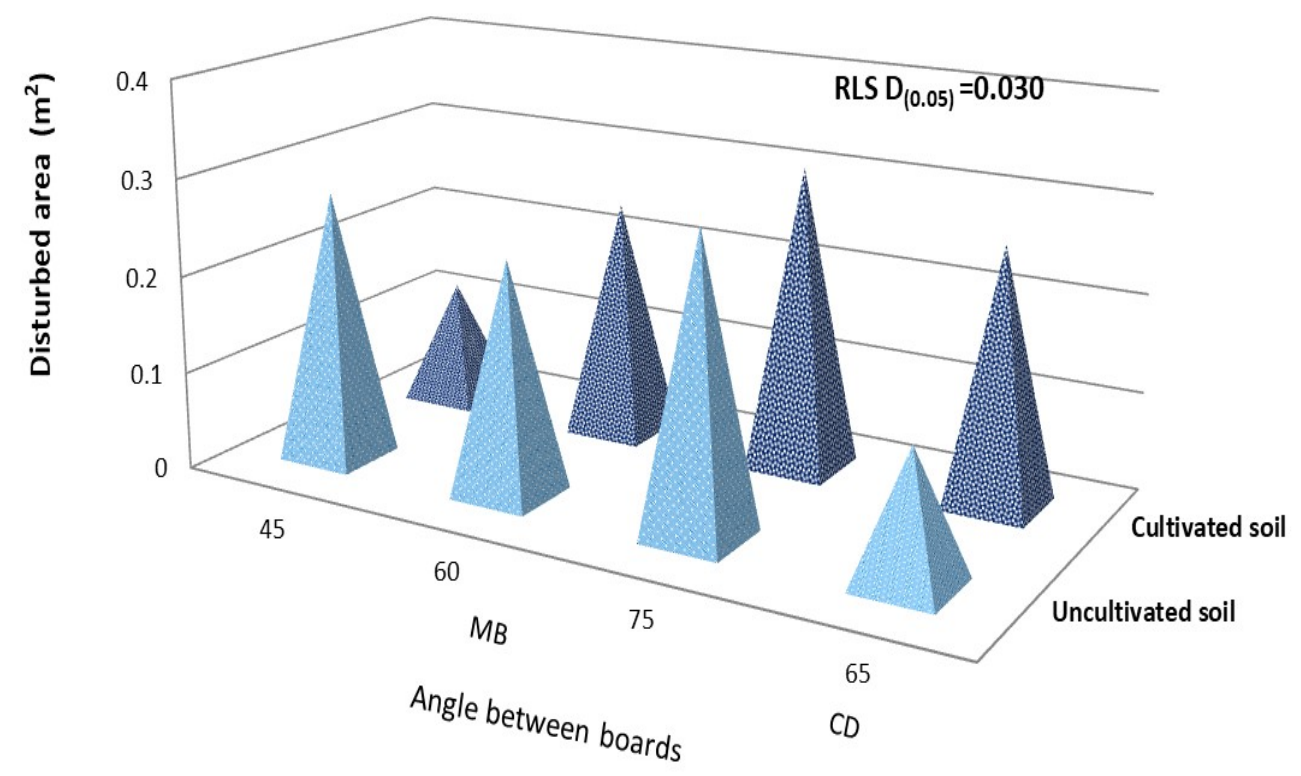

Fig. (6): The relationship between the disturbed area of $M B$ and $C D$ for different angles between the boards of MB in cultivated and uncultivated soils

\section{The interaction effect of the operating depth and the width of the wings on the disturbed area for $\mathrm{CD}$ and $\mathrm{MB}$.}

DA for MB increased with both the width of the wings of the foot and with the operating depth, however, the effect of the wings width on DA increased with operating depth, Fig. (7) . For example, for operating depth of $30 \mathrm{~cm}$, DA increased from 0.1448 to $0.1821 \mathrm{~m}^{2}(25.8 \%)$ while for operating depth of $50 \mathrm{~cm}$, it increased from 0.2888 to $0.4111 \mathrm{~m}^{2}(42.3 \%)$. Using the wings resulted in wider ditch at the bottom and soil surface. The effect of the wings is related to its ability in creating many cracks which develops to the soil surface and that resulted in greater DA and wider ditch (Aday 2015, Aday and Hmood 1995 , Mckyes and Maswaure 1997and Owen 1988)

For CD which its share width was $35 \mathrm{~cm}$ (constant), DA was higher than that for MB when the width of the wings of $\mathrm{MB}$ was $25 \mathrm{~cm}$, however, this advantage dimensioned when the wings of $\mathrm{MB}$ increased to $35 \mathrm{~cm}$ 
especially for operating depth of 30 and $40 \mathrm{~cm}$. Whereas, MB surpassed CD in producing greater DA when the wings increased to $45 \mathrm{~cm}$.

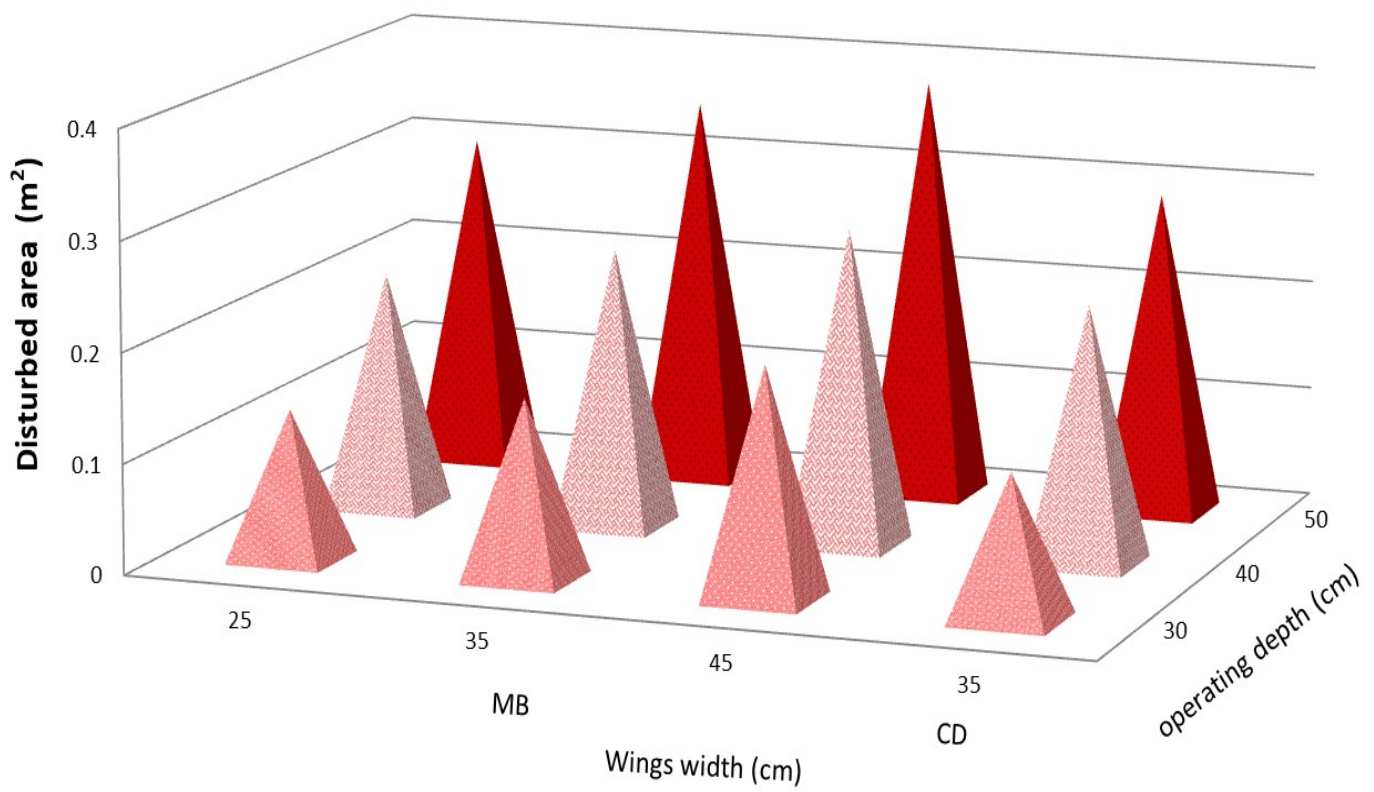

Fig. (7): The relationship between the disturbed area of $M B$ and $C D$ and the operating depth for different widths of wings of the foot of MB.

\section{ii. Conclusions}

(1) DA increased for MB with operating depth in both soil types, whereas, in cultivated soil for CD. For $\mathrm{MB}$, DA was higher in the cultivated soil compared with that in the uncultivated soil. CD could not penetrate the uncultivated soil.

(2) DA increased with angle between the boards of MB whereas, for CD the angle did not affect DA because its angle was constant.

(3) DA increased with width of wings of the foot for MB while, for CD the width of the share was constant so that did not affect DA.

(4) For MB, the operating depth increased DA more than the angle between boards, the width of the wings of the foot of $\mathrm{MB}$ and the soil types. Whereas the angle between the boards surpassed the width of the foot and soil type in giving higher DA whereas the width of the wings surpassed the soil type in giving higher DA.

\section{2- References}

(1) Aday, S.H. and M. Ramdhan (2018): Comparison between the draft force requirements and the disturbed area of a single tine, parallel double tines and partially swerved double tines subsoilers. J. Soil and Tillage research. (in press) 
(2) Aday, S.H., M. Ramdhan and H. Ali (2016):Evaluation of the field performance of partially swerved double tines subsoiler in two different soil textures and two levels of moisture contents. Part 1: The draft force requirement and disturbed area. 2nd national conference on mechanization and new technology, Ramin University of Agricultural Science and Natural Resources. Ahvaz, Khuzestan, Iran, June 2016.

(3) Aday, S.H. (2015): Theory of agriculture machines. Alghadeer Co. For Printing and Publishing Ltd. Basreah, Iraq.

(4) Aday,S.H. and A.R. Al-Haliphy ${ }^{\mathrm{a}}$ (2001): The disturbed area and the specific resistance of a modified subsoiler in heavy soil. Basrah J. Agric. Sci. 14 (3): 73-98.

(5) Aday,S.H. and M.S. Hmood (1995): The field performance of the subsoiler when provided with wings and shallow tines in heavy soils. Mesopotamia J. 7(4): 16-20.

(6) Aday,S.H. and Y.Y. Hilal (2004a): the effect of wings width on the field performance in heavy soils. The draft force and the disturbed area. Basrah J. Agric. Sci. 14(2): 79-94.

(7) Aday,S.H. and Y.Y. Hilal (2004b): the effect of lifting angle of the subsoiler foot wings on its field performance in heavy soils. The draft force and the disturbed area. Iraq J. Agric. 9(3): 195207.

(8) Aday,S.H. and M.A. Abdul-nabi and D.R. ndawii (2011): the effect of the lateral distance between the shallow tines on the disturbed area and the specific resistance of the subsoiler. Part (2).

(9) Ahmed, M.H. and R.J. Godwin (1983): the influence of wing position on subsoiler penetration and soil disturbance. J. Agric. Engng. Res. 28: 489-492.

(10) Black, C., J.L. White, J.E. Ensminger and F.E. Clark (1993): Method of soil analysis. $6^{\text {th }}$ edition. Am. Soc. Agron, Madison. Wisconsin, U.S.A.

(11) Gill, W.R. and G.E. Vandenberg (1968): Soil dynamic in tillage and traction. Agriculture hand book, No. 316 Agric. Res. Service, U.S.D.A.

(12) Godwin, R.J. and Spoor (1977): Soil failure with narrow tines. J. Agric. Engng. Res. 22: 213-228.

(13) Mckyes, E. and J. Maswaure (1997): Effect of design parameters of flat tillage tools on loosening of a clay soil. J. Soil and Tillage Research. 43: 195-204.

(14) Owen, G.T. (1988): Soil disturbance associated with deep subsoiling in compact soils. Can. Agric. Eng. 30 (1): 33-37.

(15) Spoor, G. and R.J. Godwin (1978): An experimental investigation into the deep loosening of soil by rigid tines. J. Agric. Eng. Res. 23 (3): 243-258. 